\title{
Why Is Insured Unemployment So Low?
}

THE NATION's unemployment rate has risen to new post-Depression highs since 1980. But at the same time the number of persons receiving unemployment compensation benefits has been unusually low relative to the total number of unemployed. Two types of state and federal programs are involved in this development: regular unemployment benefits and extended and supplemental benefit programs.

The regular unemployment compensation program provides benefits for a duration of about six months (twenty-six weeks) to workers on temporary or permanent layoff and to certain unemployed workers who quit their jobs for just cause. Extended and supplemental unemployment compensation programs provide benefits lasting three or more additional months to workers who exhaust their regular benefits.

During the recent recession the number of recipients of regular jobless benefits was low in comparison to the number of workers who lost their jobs. This development affected the insured unemployment rate (IUR), which is one of the nation's two most important measures of slack in the labor market. The IUR is essentially the number of recipients of regular benefits divided by the total number of jobs covered by the unemployment insurance system. ${ }^{1}$ Since the numerator of this ratio is available

Support for this research was partly provided by the Employment and Training Administration, U.S. Department of Labor, under contract 20-11-82-12. I am grateful for the substantial contribution of Daniel H. Saks, who participated in the design of this project, and for research assistance provided by Karen Hanovice. I thank Edward Fu, Joseph E. Hight, James van Erden, and Ronald Willus of the Department of Labor and Geoffrey O. Carliner, John F. Earl, Thomas J. Kniesner, and Robert A. Moffitt for their help. The views expressed here are my own and do not represent those of Brookings or the Department of Labor.

1. Technically the numerator is the number of continued claims for regular unemployment insurance, as explained below. 
within ten days of the close of each week, the IUR provides a very timely indicator of changing labor market conditions and is widely used to assess slack in the labor market.

Monthly movements in the IUR have been historically quite similar to movements in the total unemployment rate (TUR). The latter measure, which is the nation's best known indicator of labor market slack, is the ratio of all active job seekers, including persons on layoff, to the total civilian labor force. The TUR is published monthly by the U.S. Bureau of Labor Statistics and is based on survey responses in a national probability sample of about 60,000 households in the Current Population Survey.

The developments of recent years in the regular unemployment insurance program have caused a sharp break in the relation between the IUR and TUR. In 1982, when the TUR was 9.7 percent, the IUR was only 4.7 percent, or 5.0 percent lower. By contrast, in 1975 the IUR was only 2.6 points lower than the TUR-5.9 percent versus 8.5 percent.

This sharp decline in the ratio of insured to total unemployment rates may indicate deterioration of one or both measures as an indicator of labor market tightness. It is important to establish whether this has occurred and, if so, which measure is more reliable. Both unemployment indicators are used in a wide variety of policy applications. The TUR is accepted by many policymakers and the public at large as the best single indicator of the current state of the economy. The IUR is the basis for triggering extended and supplemental unemployment insurance, for measuring state and local unemployment rates, and for distributing federal funds under a variety of programs. If either statistic now provides a misleading picture of labor market conditions, the use of the statistic in policymaking should be changed.

In addition to the decline in the fraction of unemployed persons who are receiving regular unemployment compensation, there has been an even sharper drop in the fraction of unemployed receiving benefits under extended and supplemental programs. As a result the fraction of jobless workers receiving all types of benefits was lower in 1981-82 than in any other postwar recession. The contrast with experience in the 1975-76 recession is especially striking. In calendar year 1975, a little more than 78 percent of the unemployed were covered by regular, extended, or supplemental unemployment insurance. In calendar 1982 only 45 percent were covered by compensation. 
Table 1. Unemployment Insurance Outlays, Selected Fiscal Years, 1975-82

\begin{tabular}{lccccc}
\hline \multicolumn{1}{c}{ Item } & 1975 & 1976 & 1980 & 1981 & 1982 \\
\hline $\begin{array}{l}\text { Federal outlays on all unemployment insurance } \\
\quad \text { programs (billions of 1982 dollars) }\end{array}$ & 22.57 & 30.78 & 20.98 & 20.95 & 23.76 \\
$\quad$ Total unemployment rate (percent) & 7.3 & 8.0 & 6.8 & 7.4 & 9.1 \\
$\begin{array}{l}\text { Insured unemployment rate (percent) } \\
\begin{array}{l}\text { Average number of civilian unemployed } \\
\quad \text { (millions) }\end{array}\end{array}$ & 5.0 & 4.9 & 3.7 & 3.4 & 4.3 \\
\hline
\end{tabular}

Sources: Budget of the United States Government, Fiscal Year 1977, and Budget of the United States Government for fiscal years 1978, 1982, 1983, and 1984; U.S. Department of Labor, Employment and Earnings (various issues).

a. Figures derived using the Payments for Individuals deflator as published in the 1984 budget.

The countercyclical stimulus provided by unemployment insurance was also considerably lower in the more recent recession, as shown in table 1. In fiscal 1976, when only 7.6 million were unemployed, the nation spent almost $\$ 31$ billion (1982 dollars) on all unemployment insurance programs. Last fiscal year, when unemployment averaged 10 million, less than $\$ 24$ billion was spent on these programs. Thus the amount of countercyclical stimulus dropped by nearly one-fourth though the number of unemployed was higher by one-third. The real compensation per unemployed worker fell by over 40 percent.

The decline in countercyclical stimulus and income protection provided by unemployment insurance in part reflects a conscious policy choice by the president and Congress to reduce the scope of extended and supplemental unemployment benefits. ${ }^{2}$ The effect of these policy changes was compounded by the low level of IUR relative to TUR because a state's eligibility for extended unemployment benefits is determined by its insured unemployment rate.

In this paper I examine the pattern of insured and total unemployment over the past three decades and attempt to explain their recent divergence. The paper begins with precise mathematical definitions of the TUR and IUR, followed by an examination of their historical relation. Using information on the regular unemployment insurance program provided by the Unemployment Insurance Service and the BLS, I show

2. In 1981 the national trigger for extended benefits was eliminated and the trigger for extended benefits at the state level was raised considerably. Federal supplemental benefits are of shorter duration and were begun at a later point in the business cycle than the supplemental benefits that were available in the 1975-76 recession. 
why the IUR/TUR ratio varies over the business cycle and over time and suggest some reasons why it may have shifted so abruptly after 1980 . The subsequent section focuses on insurance coverage under the extended benefit and supplemental benefit programs. The countercyclical stimulus and income protection provided by these last two programs are especially important when the average duration of unemployment is long, as it is at the end of a deep recession. The paper concludes with a summary of policy implications.

\section{Insured and Total Unemployment Rates}

The regular unemployment insurance system provides two weekly statistics of wide interest to labor market analysts and economic forecasters: the insured unemployment rate and the level of initial claims for unemployment insurance (UI). Initial claims are filed by job losers and job leavers to notify the unemployment insurance office that a spell of unemployment or underemployment has begun. If the initial claimant has had no recent experience of unemployment, the office determines eligibility and, for unemployed or underemployed workers who qualify, computes a benefit award.

In most states, workers must be unemployed for one week before becoming eligible for payments. After that week's delay, job losers file "continued" claims for additional weeks of benefits. Job leavers, if they are eligible for benefits at all, must usually wait several weeks before benefits commence. ${ }^{3}$ Applicants who qualify file continued claims until they stop searching for work, become reemployed, or exhaust their claim to compensation. In most states, workers exhaust their regular compensation after about twenty-four to twenty-six weeks of benefits, although the duration of those benefits varies by state and depends on the specific work history of the individual. In states in which the extended benefit program is in effect, claimants who have exhausted their regular unemployment benefits may continue receiving payments under the extended program. Similarly, when a supplemental federal program is in effect, workers who have exhausted both regular and extended benefits become eligible for supplemental benefits. Beneficiaries under the ex-

3. Many states do not permit persons who quit their last job to draw benefits. In the remaining states, the waiting period for benefits varies considerably. 
tended and supplemental programs are excluded in computing the insured unemployment rate.

To be eligible for benefits, an initial claimant must have a recent work history meeting certain minimum requirements. These requirements vary considerably across states. Workers must have had covered earnings in a minimum number of recent quarters, have attained a minimum level of total earnings, or have both to be eligible. ${ }^{4}$ In determining a worker's eligibility status, states typically take account of covered earnings in the first four of the most recent five completed calendar quarters. Consequently, unemployed persons who are new entrants to the labor market, reentrants with no recent work history, or job losers and job leavers with only brief recent employment histories will not be eligible for benefits. Unemployed workers who claim benefits, then become reemployed without exhausting them, and then again lose their jobs within a year of the start of their first spell of unemployment can resume receipt of payments under their first benefit award. These payments can continue until workers exhaust their initial twenty-six week award. At the start of the next benefit year, which begins fifty-two weeks after the start of workers' first spell of joblessness, they may become eligible for a new benefit award if enough covered wages have been accumulated. But workers who become unemployed twice during a single benefit year will often be eligible to receive fewer weeks of benefits during their second spell of joblessness than during their first.

\section{IUR AND TUR DEFINITIONS}

As mentioned above, the IUR is the ratio of continued claimants for regular unemployment insurance to the average number of persons in covered employment in four recent quarters. ${ }^{5}$ By comparison, the total

4. Covered earnings are earnings paid on jobs covered by the UI system. An estimated 97 percent of all paid employment is now covered by the system.

5. Technically the covered employment measure provides a count of jobs, not persons. A single individual may work in two or more jobs, and each of that person's employers will separately report the worker's earnings to the unemployment insurance system. Also, certain recipients of regular benefits are excluded in determining the number of continued claims. Those not counted are recipients under the unemployment compensation programs for federal workers, ex-servicemen, and railroad workers covered by the railroad retirement program. Since only a relatively small number of unemployed workers is covered by these programs, they will be ignored in the remainder of this section.

The number of jobs covered by unemployment insurance is only known after employers 
unemployment rate is the number of job losers, job leavers, labor market entrants, and reentrants who are unemployed divided by the total civilian labor force, which includes both the currently employed and unemployed. More formally,

$$
I U R_{t}=\frac{I U_{t}}{\overline{C E}_{t}} \cdot 100
$$

where

$$
\overline{C E}_{t}=\sum_{i=t-18}^{t-7} \frac{C E_{i}}{12}
$$

and

$$
T U R_{t}=\frac{U_{t}}{E_{t}+U_{t}} \cdot 100
$$

where $I U_{t}$ is the number of insured unemployed and underemployed in month $t ; C E_{i}$ is the number of employed workers covered by unemployment compensation in month $i$; $U_{t}$ is the total number of civilian unemployed; and $E_{t}$ is the total number of civilian employed. ${ }^{6}$ Given the differences in definition, there is no reason to expect the two measures will coincide in a particular month.

Obviously the total number of unemployed, $U_{t}$, must exceed the number of insured unemployed, $I U_{t}$, because the latter excludes all new entrants, most reentrants and job leavers, and nearly all job losers whose

file wage and payroll information required for the calculation and administration of the unemployment insurance payroll tax. Because this information takes several months to collect and compile, the measure of covered employment used in the IUR is always several months out of date. In computing the IUR, the Department of Labor uses a four-quarter moving average of covered employment. At the beginning of each calendar quarter, this information covers the period from eighteen to seven months before the current month; by the end of a quarter it covers the period from twenty to nine months before the current month. For excellent descriptions of the IUR, see Gloria P. Green, "Measuring Total and State Insured Unemployment," Monthly Labor Review, vol. 94 (June 1971), pp. 37-48; and Saul J. Blaustein, "Insured Unemployment Data," in National Commission on Employment and Unemployment Statistics, Counting the Labor Force, appendix, vol. 2: Data Collection, Processing and Presentation: National and Local (U.S. Government Printing Office, 1979), pp. 198-252.

6. About 6 percent of regular UI recipients in a given week are partially rather than fully unemployed. 
current spell of unemployment is longer than twenty-six weeks. ${ }^{7}$ Hence the numerator of the IUR is smaller than that of the TUR. The denominator is also smaller, because it excludes the unemployed and also those employed persons (such as the self-employed) not covered by unemployment insurance. Furthermore, because it is based on a lagged value of employment, it will be a couple of percentage points smaller than current employment any time that employment is growing rapidly, as it was in the late 1970s.

The historical relation between the insured and total unemployment rates is shown in figure 1. One feature of the relation is apparent upon casual inspection: the ratio of insured to total unemployment rates has been declining for the past three decades. Until 1955 the two rates were very similar. Since that time there has been a growing divergence between the two rates, and the divergence has accelerated since 1980. Both the trend and cycle reflect changes in the composition of the unemployed. But these changes fall well short of explaining the sharply growing divergence between the two rates since 1980 .

To understand the historical relation between the IUR and TUR, it is useful to partition the total change in their ratio between a change in covered employment and a change in covered unemployment. Definitions 1 and 2 can be combined to yield

$$
\frac{I U R_{t}}{T U R_{t}}=\frac{I U_{t}}{U_{t}} \cdot\left[\frac{\left(E_{t}+U_{t}\right)}{\overline{C E}_{t}}\right] .
$$

During the three decades from 1951 to 1980 the IUR/TUR ratio fell by about 40 percent, from 0.91 to 0.54 . During that same span the ratio of the civilian labor force to UI-covered employment-the ratio in brackets-fell by about one-third. This decline was caused by a series of revisions in federal and state UI laws that have progressively broadened the population covered by unemployment insurance. (The fraction of all civilian employment covered by UI rose from 58 percent in 1951 to 87 percent in 1980.) Other things equal, the fraction of unemployed covered by the program would be expected to rise along with the fraction of employed who are covered. However, in the same thirty-year span, the ratio of insured to all unemployed, IU/U, actually dropped from 48 to 44 percent.

7. However, a small number of part-time workers receiving partial unemployment benefits are counted among the insured unemployed even though they would be excluded from the CPS count of unemployed. 


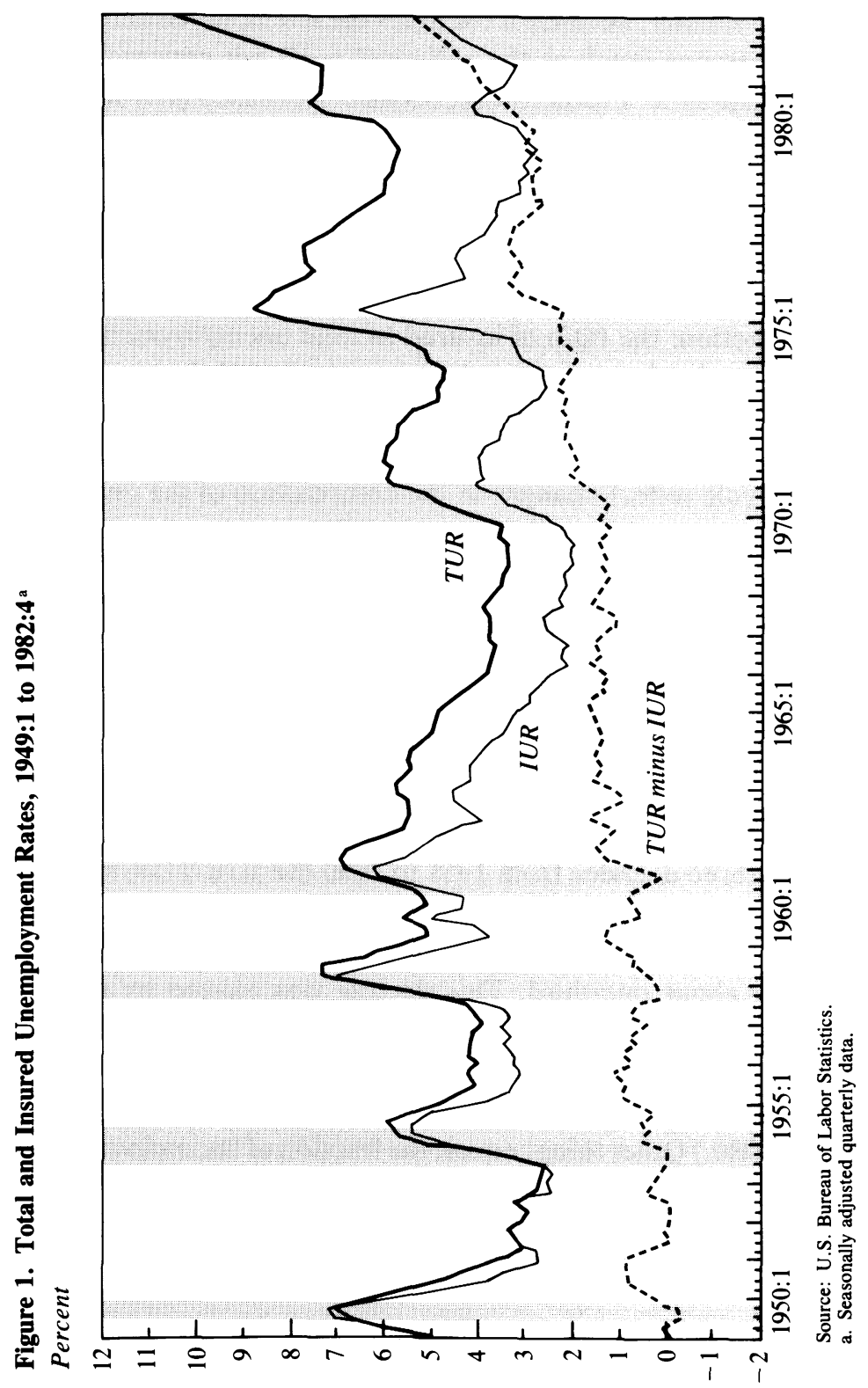




\section{DECLINING RATIO OF INSURED TO TOTAL UNEMPLOYED}

The main cause of the decline in the ratio of insured to total unemployed before 1980 was the changing demographic composition and industrial attachment of the jobless. In the mid-1950s nearly half of all unemployed workers were men over the age of twenty-four. These unemployed tend to be experienced workers who are job losers and hence eligible for jobless benefits. Over the 1960s and 1970s prime-age men came to represent a sharply lower fraction of all unemployed, dropping to about one-quarter of the total in 1973-74. Young men and women under twenty-five years who are much more rarely eligible represented a much higher fraction, with the fraction of all unemployed who are under age twenty-five rising from less than a third in 1951 to over a half in 1973-74. The result of this demographic shift, not surprisingly, was a decline in the ratio of insured to total unemployed.

In addition, during this same period there was a shift in the nation's industrial structure away from industries in which UI coverage ratios were high. Goods-producing industries such as mining, manufacturing, and contract construction have declined in relative importance while service-producing industries have grown. Even with the extensions in UI coverage mandated by federal law, a relatively low proportion of unemployed workers from service industries is covered by jobless benefits. Although the limitations in available data do not permit an estimate of their separate effects, it is likely that the combination of demographic and industrial shifts can account for the secular decline in the IU/U ratio over 1951-80. ${ }^{8}$ However, no abrupt shift in demographic

8. The effects of the demographic and industrial shifts can be estimated from published information about UI coverage ratios among specific demographic and industrial groups of the unemployed. With the assumption that these ratios remained constant over the 1951-80 period, one must multiply the coverage ratios by the fraction of unemployed in the respective groups in 1951 and 1980 and then compute the predicted ratio of coverage for the entire population of unemployed in those two years. Exercises of this type, using coverage ratios for 1960, 1967, 1973, and 1977 as baselines, show that industrial and demographic shifts together can account for a substantially larger decline in the IU/U ratio than the one that actually occurred. The discrepancy is explained by the fact that Congress has extended UI coverage over 1951-80, so coverage ratios for some individual groups of unemployed workers rose over the same period. Without the UI extensions, the decline in the IU/U ratio would have been much greater. 
and industrial patterns has occurred since 1980 to correspond to the sharp relative drop in $\mathrm{IU} / \mathrm{U}$ since that year.

The cyclical pattern in the IU/U ratio stems from a different kind of distributional effect. At the onset of a recession, firms discharge a large number of workers, most of whom will be eligible for jobless benefits. During this phase of the cycle, job losers account for a rising percentage of all unemployed, and the ratio of insured to total unemployed rises rapidly. As the recovery begins, workers on temporary layoff are recalled, although the number of unemployed new entrants and reentrants may continue to mount. The ratio of insured to total unemployed begins to fall and continues to do so until business conditions (and the TUR) stabilize. If the slump is protracted, the ratio of insured to total unemployed will also fall as discharged workers begin to exhaust regular benefits, about six months after the beginning of a downturn. Thus a decline in the number of insured unemployed may not necessarily signal the start of a recovery in the labor market. It may only reflect the fact that the recession has become so lengthy that many job losers have dropped out of the ranks of the insured unemployed.

\section{POST-1979 EXPERIENCE}

Secular and cyclical changes in the composition of the unemployed appear to account for most if not all of the fluctuations in the IU/U ratio before 1980, but do not explain experience since that year. To examine the most recent experience it is useful to focus on only a certain portion of the civilian unemployed-job losers. ${ }^{9}$ Before 1980 the number of jobless who were covered by unemployment insurance was usually within a few percentage points of the number of unemployed who lost their last jobs within the past twenty-six weeks. The correspondence between these two statistics should hardly be surprising. New entrants, reentrants, and persons unemployed longer than twenty-six weeks are hardly ever eligible for regular UI, and only a small fraction of voluntary job leavers qualify for benefits. Consequently, the IU/U ratio has varied

9. In fact, it would be worthwhile to examine the entire postwar relation between the number of regular insured unemployed and the number of job losers. Information on the number of job losers among the unemployed only dates back to 1967 , however, so it is not possible to analyze this relation much beyond the period covered in the text, that is, 1968 through 1982. 
over time and varies over the business cycle in much the same way as the ratio of short-term job losers to total unemployed, a ratio denoted here as $L U_{26 w k} / U$. Reliable CPS information about the number of job losers goes back to about 1968. A regression using quarterly data (not seasonally adjusted) for 1968-79 gives the following (standard errors in parentheses):

$$
\frac{I U}{U}=\underset{(0.01880)}{-0.00094}+\underset{(0.050)}{0.082} \cdot \frac{L U_{26 w k}}{U} ; \quad \bar{R}^{2}=0.908 .
$$

Since the constant term is almost zero, the regression indicates that at any point in time, and with only minor disturbances, $I U / U$ is 108 percent of $L U_{26 w k} / U$. The number of insured unemployed exceeds that of shortterm job losers for several reasons. The former includes part-time workers receiving partial unemployment insurance, who constitute about 6 percent of UI recipients in an average week, and it also includes individuals who voluntarily left their last jobs but for reasons that made them eligible for regular unemployment benefits. ${ }^{10}$ Both these groups are excluded from the CPS count of short-term job losers.

As noted above, the results in equation 4 are based on experience in 1968-79. Since that time there has been an abrupt shift in the relation between the total of insured unemployed and recent job losers, which corresponds to the recent decline in the IUR/TUR ratio. The magnitude of the shift is estimated by extending the period covered by the previous regression up through 1982:3 and using dummy variables for the past three years $(D 8082$, a dummy variable with the value of 1.0 for quarters in $1980-82$; and $D 8182$, a dummy for quarters in 1981-82):

$$
\begin{array}{r}
\frac{I U}{U}=\underset{(0.001)}{0.001+}+\underset{(0.050)}{1.077} \cdot \frac{L U_{26 w k}}{U}-0.103 \cdot\left[\frac{L U_{26 w k}}{U} \cdot D 8082\right] \\
-\underset{(0.028)}{0.132} \cdot\left[\frac{L U_{26 w k}}{U} \cdot D 8182\right] ; \quad \bar{R}^{2}=0.894
\end{array}
$$

According to these results, the ratio of insured unemployed to short-

10. The results in equation 4 could presumably be improved by excluding these workers, but there is no available information on UI-covered workers who are job leavers (as distinct from job losers). 
term job losers declined from its average of 1.077 in 1968-79 to 0.974 in 1980 and to 0.842 in 1981-82. Thus in 1981-82 the number of insured unemployed relative to short-term job losers was down by 22 percent (0.235/1.077). This implies that in an average week in 1982, about 1.1 million fewer workers received regular UI benefits than would have been expected on the basis of previous historical experience.

There are only a few reasons why the ratio of insured unemployed to job losers falls. Among new job losers, fewer may be eligible to apply. Among eligible job losers, a smaller number may apply. Among applicants, a greater fraction may be disqualified before receiving first payment. And among accepted applicants, the potential duration of an award may decline. In trying to decide which of these has occurred, one is faced with a serious limitation. There exists no nationally representative data set containing enough information to determine who among the unemployed is eligible for jobless benefits and, of those, who is receiving benefits. The ideal data set would contain work and benefit histories going back two and one-half years. Earnings histories dating back that far might be needed to determine a current benefit entitlement. Data on benefit receipts during the most recent year are necessary to determine who among the unemployed is receiving benefits and who has already exhausted compensation in the current benefit year. In the absence of this kind of detailed information one must rely on indirect evidence provided by comparisons of CPS and UI administrative data. The CPS, however, does not even contain current information identifying recipients of UI benefits.

The CPS data identify the number of new job losers monthly. (For this purpose a good indicator is the number of job losers unemployed fewer than five weeks.) This total can be compared to the average weekly number of initial UI claims, $I C$, to determine the probability that job losers apply for UI benefits. The regression below relates quarterly data on these two series for 1968:1 through 1982:3, with dummy variables again used for the last three years:

$$
\begin{aligned}
& I C=-16,937+0.382 \cdot L U_{5 w k}-0.016 \cdot\left(L U_{5 w k} \cdot D 8082\right) \\
& (11,298) \quad(0.012) \\
& -0.045 \cdot\left(L U_{5 w k} \cdot D 8182\right) ; \quad \bar{R}^{2}=0.965 \text {. } \\
& \text { (0.009) }
\end{aligned}
$$

The negative coefficients on $L U_{5 w k} \cdot D 8082$ and $L U_{5 w k} \cdot D 8182$ imply that 
initial claims were somewhat lower than usual in 1980 and were sharply lower than normal in 1981 and 1982, by which point claims were running about 16 percent below the level that would be predicted from experience during 1968-79.11

This finding implies either that fewer job losers considered themselves eligible for benefits or that, if they considered themselves eligible, fewer bothered to apply. (Note that initial claims may be filed by persons who later turn out to be ineligible.) It is difficult to distinguish between these two possibilities. To shed light on this question I used CPS data to compare job losers in the first quarter of 1982 with job losers in the first quarter of 1976. The year 1976 was chosen for comparison because unemployment at that time was reasonably high ( 7.7 percent versus 8.8 percent in 1982:1), and also because unemployment had been high for nearly a year and a half.

Job losers unemployed fewer than five weeks in 1976 were relatively more likely to be under age twenty than were identically defined job losers in 1982 (16 percent in 1976 versus 10 percent in 1982), and they were less likely to be males over age twenty ( 54 percent versus 59 percent). These demographic differences suggest that a lower fraction of new job losers would claim jobless benefits in 1976; yet the actual fraction filing initial claims was about 17 percent higher. Although the standard industrial classification (SIC) codes of job losers are not included in data from the BLS, available data can be used to compare the industrial classification of all unemployed workers in 1976 and 1982. These differences do not appear to be significant, at least on the level of the one-digit SIC code.

Another potential difference between 1976 and 1982 is that job losers in the latter year may have experienced more unemployment during the previous period. As mentioned above, to be eligible for jobless benefits, a job loser must have sufficient covered earnings in four previous calendar quarters. If 1982 job losers experienced more joblessness in 1981 than 1976 job losers experienced in 1975, a smaller proportion of 1982 job losers would be eligible for benefits. Special tabulations using the March 1976 and March 1982 CPS files provided no support for this hypothesis. In the March CPS, workers were asked to report the number

11. The reduction in claims is $(-0.016-0.045) / 0.382=-16$ percent. Since the estimated constant term is very low in relation to the average number of weekly initial claims, this approximation is reasonably accurate. 
of weeks worked in the previous calendar year. Based on the replies of 615 respondents in 1976 and of 1,165 in 1982, it appears that new job losers in 1982 were employed for more weeks during the previous year than were 1976 job losers (thirty-five weeks for 1982 job losers versus only thirty-two weeks in 1976). ${ }^{12}$ Thus there appears to be nothing in the previous work experience, demographic composition, or industrial classification of 1982 job losers to explain their low application rate for unemployment benefits. On the contrary, the differences between them and job losers in 1976 are consistent with a higher application rate in 1982.

Although the 16 percent relative decline in initial claims during 1981 and 1982 is very significant, it may not be large enough to explain the entire 22 percent drop in the ratio of insured unemployed to job losers mentioned above. To account for the rest of the drop, UI offices must either have denied benefits to a higher percentage of initial claimants or have made benefit awards of shorter duration to successful claimants. There is no evidence that an abnormally high fraction of claimants was denied benefits in $1980-82$. In that period only 13 percent of claimants was denied awards because of insufficient wage credits. This is 3 percentage points below the comparable rate over 1971-79. Similarly, the total number of benefit denials was in line with figures for the 1970s. ${ }^{13}$

Some evidence exists that the average period of benefit awards was briefer in 1980-82 than in earlier periods. It should be recalled that there are two types of initial claims filed in a given week: those filed by claimants who did not begin a previous spell of insured unemployment in the previous year (categorized "new") and those filed by claimants who received benefits in the past ("additional"). (The latter claimants file additional initial claims, which are included in the total count of initial claims.) The Unemployment Insurance Service compiles statistics on the potential length of benefit awards made to successful new UI claimants. Virtually no trend in the average duration of these new awards has been apparent in the past several years. It has remained around twenty-four and a half weeks for the past decade. However, the fraction

12. In both cases the job losers considered are those who reported being unemployed fewer than five weeks on the March CPS. For job losers unemployed more than five but fewer than twenty-six weeks there appears to be virtually no difference in work experience during the previous year (1975 and 1981).

13. The number of denials as a fraction of monetary determinations was 32 percent in both 1980-82 and 1971-79. 
of claimants who have previously received benefits has risen sharply in the past three years. The ratio of these additional claims to all initial claims averaged 37 percent from 1971 through 1979, but rose to 42 percent in 1980-81 and to 47 percent in 1982. Because these additional claimants have already used up a portion of their potential benefit award, their potential weeks of benefits under the additional claims will typically be less than for new initial claimants. Hence the rise in the number of additional claimants probably implies that among all initial claimants, new as well as additional, there has been a decline in the duration of expected benefits.

The analysis up to this point suggests two main reasons for the decline in the ratio of insured unemployed to short-term job losers in 1980-82. Fewer new job losers are applying for benefits and, among initial claimants, the expected length of benefits has declined because a higher fraction has recently received benefits. There is no evidence that the demographic composition, industrial classification, or recent work history of 1980-82 job losers has caused the decline in coverage. Why then has the number of initial claims fallen?

\section{CHANGES IN UNEMPLOYMENT INSURANCE ADMINISTRATION}

A number of factors could explain the drop in new jobless claims. Several legal and administrative changes have been made in the unemployment insurance system since the last major recession in 1975-76. The most important of these have been the significant broadening of the population covered; a tightening of eligibility standards for those who quit a recent job; the imposition of a high implicit tax on pensions, annuities, and old-age insurance; the imposition of federal taxation on UI benefits; and the revision of the trigger mechanism for extended UI benefits. Clearly the first of these reforms should have raised the number of jobless claims in 1980-82. But since the newly covered workers were employees in state and local government and agricultural establishments, it is not likely that the number of initial claims should have risen very much in a recession.

The tightening of eligibility criteria for job leavers does not appear to me to be very significant. A number of states that formerly permitted quitters to obtain benefits after a disqualification period now prohibit them from receiving benefits. However, too few large states have been 
affected by this change for it to have much importance in the recent recession. Also, if the trend were significant one would expect initial claims to have declined in 1978-79 when job leavers comprised a large portion of the unemployed rather than in 1981-82 when quit rates were lower.

The revised treatment of pension income under the UI system could have some effect on older unemployed workers. Formerly, workers receiving private pensions or social security retirement benefits were eligible for full jobless benefits if discharged from a job. Many workers retiring from a job or taking early retirement benefits after being discharged consequently received both UI and a pension. By 1980 all states were compelled by the federal government to revise this provision. Now if a worker is discharged from a job and accepts a pension from the firm that put that person on layoff, UI benefits during the subsequent spell of unemployment are reduced by the amount of the pension. Similarly, social security benefits are now also counted in determining the level of a weekly UI award. This reform should reduce the number of jobless claims filed by older unemployed workers. Available information on the characteristics of the insured unemployed provides some evidence for a decline in insured unemployment among older workers. But because older workers represent only a small portion of the unemployed, even a major impact on their participation would have only a limited effect on total jobless claims. ${ }^{14}$

Taxation of unemployment compensation is probably the reform that has affected the value of jobless benefits for the greatest number of potential recipients. Married couples with total incomes above $\$ 18,000$ and single individuals with incomes above $\$ 12,000$ are now required to pay federal taxes on some or all unemployment compensation received. Before 1979, jobless benefits were exempt from taxes. The taxation of benefits significantly reduces their value to upper- and even middleincome families. If benefit taxation is a significant factor in deterring UI applications among otherwise eligible jobless workers, it could be expected to have a disproportionate effect on unemployed workers in the upper part of the income distribution. It is unfortunate that regularly

14. For example, in 1975 claimants age sixty-five and older comprised less than 5 percent of the UI rolls. Only a minority of older workers are eligible for a private pension. 
collected information about the income distribution of UI recipients is almost wholly lacking. ${ }^{15}$

The most recent major revision in UI law was the significant tightening of the trigger mechanism in the extended benefit program. By eliminating the national unemployment rate trigger and raising the state trigger, this reform drastically reduced the availability of extended benefits during the recent recession. But it has had no direct effect on the operation of the regular UI program, and it is consequently difficult to see how it could affect applications for regular benefits.

One final development in the UI system should also be noted. Because of a relative cutback in administrative funding in the past two years, state employment security agencies have been forced to reduce the number of offices in which employment services are offered. This has principally affected the Job Service, where the funding cutbacks have been concentrated, rather than the Unemployment Insurance Service, which has responsibility for handling UI claims. Nonetheless, some of the closed offices probably offered both types of services. This cutback caused some applicants to travel greater distances in order to file claims, and probably caused others to endure longer waits to file their claims. The added burden of filing a claim may have deterred some potential UI applicants, although this effect was probably small. One indication that the UI system was not overwhelmed by the recent recession is the fact that the average lapse between an initial application for benefits and the first payment stayed short throughout the recession and remained significantly shorter than the lapse during the previous recession in 1974-75.

Although none of the administrative or legal changes mentioned above appears to be important enough to explain a major part of the decline in initial claims, some of them may have affected the number of weeks over which benefits were received. The taxation of UI benefits and the cutback in extended benefits may have reduced some of the adverse incentives of unemployment insurance for labor supply and thus may have affected the IUR/TUR ratio. For example, the reduced availability of extended

15. Information about UI receipt is collected annually in the March CPS interview, when respondents are asked to report the amount of unemployment insurance and all other income received in the previous calendar year. UI benefits are so poorly reported on this survey that I could make no reliable comparisons of the income distribution of UI recipients in the 1970 s and early 1980 s. 
benefits may have caused workers nearing the end of their period of regular benefits to search harder for jobs than did comparable unemployed workers in the 1975-76 recession, when benefits under regular, extended, and supplemental programs could extend up to sixty-five weeks. The best estimate of the incentive arising from shortened benefit duration is that provided by Moffitt and Nicholson, who estimate that a ten-week reduction in potential jobless benefits causes a one-week decline in the duration of an average spell of covered unemployment. ${ }^{16}$ Note that if the average jobless spell of insured unemployed workers falls by a week, while the average spell of uninsured workers remains unchanged, the overall fraction of insured weeks to all weeks of unemployment declines. Consequently, any reduction in adverse incentives arising out of UI may reduce the ratio of insured to total unemployment in a given week. (The same effect, of course, could result from the reduction in the net earnings replacement rate caused by the recent taxation of UI benefits.)

This review of the legal and administrative changes in unemployment compensation suggests that the reform in the treatment of pension recipients and the taxation of UI benefits are the developments with the greatest potential for reducing applications. The other changes either had the reverse effect or deterred applications only slightly. The relative rise in the number of initial claims categorized as additional and the recent reduction in adverse UI incentives may have the greatest potential for reducing insured spells in comparison to uninsured spells of unemployment. Unless the disposition to apply for benefits has fallen for other reasons, such as increased program stigma or lower need, the factors just mentioned appear to be the main plausible explanations for current low rates of new claims and insured unemployment. Demographic, industrial, and work experience characteristics among recent job losers do not appear to account for the low rates.

16. Robert Moffitt and Walter Nicholson, "The Effect of Unemployment Insurance on Unemployment: The Case of Federal Supplemental Benefits," Review of Economics and Statistics, vol. 64 (February 1982), pp. 1-11. This estimate is restricted to long-term job losers since it is based on persons who have exhausted regular and extended benefits and qualify for federal supplementary benefits. 


\section{Insured Unemployment under Extended and Supplemental Programs}

The previous section examined possible determinants of the insured unemployment rate, which is based on the number of unemployed covered by regular UI benefits. Although there has been an unexpected decline in the fraction of unemployed job losers covered by regular jobless benefits, a major reason for the relative drop in the total number of persons receiving UI benefits of all kinds in 1981-82 has been the cut in programs to help the long-term unemployed-namely, the extended and supplemental programs. As mentioned above, the extended benefit program was recently modified to limit the number of states participating in the program. Since October 1982, extended benefits have been available only in states in which the insured unemployment rate exceeds 5 percent and is at least 120 percent of the comparable level in the two previous years. States may also provide benefits when the IUR reaches 6 percent, regardless of the rate in previous years. Before October 1982, the extended benefit trigger rates were one percentage point lower. In addition, until 1981 the trigger rates were computed by including recipients of both regular and extended benefits in the numerator. ${ }^{17}$ Finally, before 1981 the extended benefit program had a national trigger that permitted all states to offer extended benefits when the national trigger rate exceeded 4.5 percent.

As a consequence of the reforms enacted since 1981, a smaller number of states offers extended benefits. At the end of 1982 only fourteen states with particularly high insured rates were offering extended benefits. If the pre-1981 law had been in effect, all fifty states would have been participating, as they were during the 1975-76 recession. Over the seven quarters from January 1981 through September 1982, a weekly average of only 330,000 workers was covered by extended benefits. In 1975-76, when the total number of jobless was about 17 percent smaller, the number of workers covered by extended benefits averaged 535,000 a week. Some part of the decline is due to the relative drop in claimants under regular UI programs, since as the number of these claimants falls

17. Thus the trigger rate used before 1981 was not identical to the published IUR, which excludes recipients of extended benefits from the numerator. 
the number who will exhaust benefits and apply for extended benefits also falls. This factor accounts for less than half of the observed drop, however, since the number of new regular claimants was down only about 16 percent while the number of extended benefit claimants was down 38 percent. One indirect effect of the decline in insured regular claimants is the decline in the IUR, which triggers state extended benefits. Presumably, even under the revised trigger mechanism, a greater fraction of states would qualify for these benefits if the IUR were one-fifth higher.

Until October 1982, the unemployment insurance system offered no income protection beyond thirty-nine weeks in states qualifying for extended benefits and beyond twenty-six weeks in those states not qualifying for those benefits. This was in marked contrast to experience in the 1975-76 recession when federal supplemental benefits (FSB) were available. The FSB program began in January 1975, only six months after unemployment began its rapid rise in 1974. This program extended the potential duration of unemployment insurance payments in all states by twenty-six weeks, to a total of about sixty-five weeks. During 1975 and 1976, a weekly average of 1.1 million recipients were covered by FSB, or about 14 percent of the average number of unemployed. The federal supplemental compensation (FSC) program, which took effect in October 1982, is similar in most respects to the earlier FSB program, but is considerably less generous. While the earlier program extended potential benefits by twenty-six weeks, the FSC program now offers only an added eight weeks of benefits in states with low insured unemployment and an added sixteen weeks in states with high insured rates. States with intermediate rates receive an intermediate number of additional weeks.

Figure 2 shows the fraction of all unemployed covered by regular, extended, and supplemental unemployment insurance programs. The shaded area in this figure represents the fraction of the unemployed receiving unemployment insurance under the supplemental unemployment assistance and FSB programs in 1975-77 and the FSC program in 1982. It is evident from this figure that the absence of a supplemental program before October 1982 is an important reason for the difference in coverage between the $1975-76$ and $1981-82$ periods. The restricted nature of the extended benefit program in 1981-82 is another important factor.

From the point of view of income protection, the most striking feature 
Figure 2. Fraction of Unemployed Covered by Unemployment Insurance Programs, 1947-82

Fraction covered

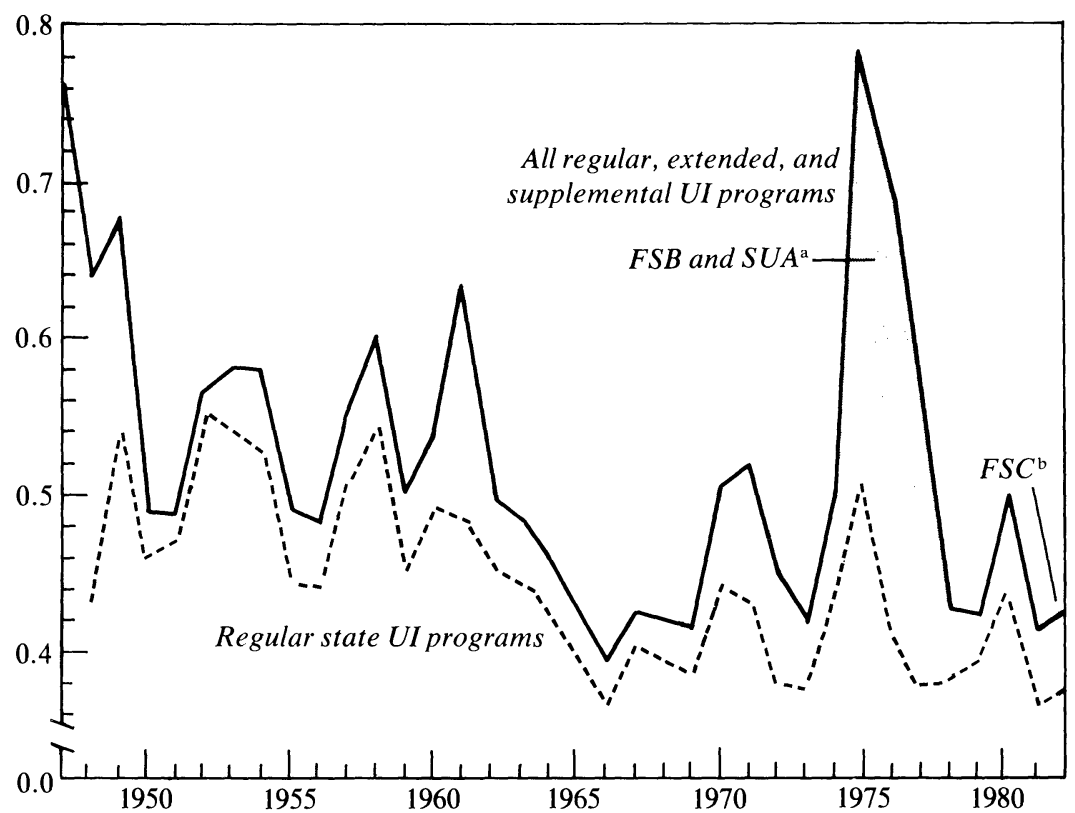

Source: Economic Indicators, various issues, and 1980 Supplement to Economic Indicators (U.S. Government Printing Office, 1980), p. 41.

a. Federal supplemental benefit program and supplementary unemployment assistance program.

b. Federal supplemental compensation program.

in figure 2 is the enormous decline in the fraction of unemployed collecting insurance under any program in the recent period, particularly in comparison to 1975-76. Only about 45 percent of the unemployed were covered by unemployment insurance in 1982; nearly 78 percent were receiving jobless benefits in 1975 . Some critics of unemployment insurance might fault the comparison with 1975-76 because benefits in that period were unusually generous, lasting up to sixty-five weeks irrespective of a worker's financial need. However, even in comparison to earlier recessions when unemployment insurance was less generous, benefits provided in 1981-82 covered an unusually small fraction of the unemployed. Except during the comparatively mild recession in 1970-71, at least 56 percent of the unemployed received jobless benefits in every 
postwar recession through 1977 . Since that year fewer than half the unemployed have been covered by jobless benefits.

\section{Implications}

A principal reason why the number of jobless collecting unemployment benefits was low during the 1981-82 recession is that the president and Congress decided it should be low. By significantly tightening the trigger mechanism in the extended benefit program and failing to enact a supplemental program similar to the one available in $1975-77$, the administration and Congress essentially denied jobless benefits to a large fraction of workers who would have been eligible to receive benefits during the 1970 s. There is no mystery about why this occurred. Interpreting the 1980 election results as a mandate for less spending on social insurance and welfare programs, public policymakers reduced the income protection available to workers during long spells of joblessness. Some of the specific reforms, such as the elimination of the national trigger for extended benefits, were quite sensible. But the collective effect of the reforms was to significantly reduce income protection and countercyclical stimulus from unemployment compensation in the midst of the worst economic downturn since the Great Depression.

The decision to significantly reduce the potential duration of unemployment benefits coincided with an unexpected drop in the IUR relative to the TUR. The former is computed solely on the basis of statistics compiled under the regular twenty-six-week program, and so it is not directly affected by the reforms in the extended benefit program or by the failure to enact a supplementary program. Yet the relative number of short-term job losers covered by regular jobless benefits dropped by 22 percent. Contributing to this decline was a 16 percent drop in the fraction of new job losers who filed initial claims for regular benefits.

The 16 percent drop in new applications cannot be explained easily with available data. However, on the basis of indirect evidence it appears that there has been no significant drop in the technical eligibility of recent job losers. It is extremely suggestive, for example, that UI offices are finding a higher proportion of applicants to be eligible for benefits than were found eligible in the past. According to CPS data, the demographic composition and industrial classification of recent unemployed workers 
is, if anything, consistent with an above-average application rate. Similarly, the employment experience of job losers appears to be no worse now than it was in the mid-1970s, when application rates for regular benefits were much higher. Legally and administratively, the main changes in the regular UI program since 1978 have been the implicit taxation of private pension and social security benefits, the imposition of federal and state taxation on UI benefits paid to high-income families, and perhaps a cut in the number of offices in which benefits can be claimed. For certain UI applicants these reforms significantly reduced the after-tax value of UI benefits or raised the costs of application. These reforms seem to me to be insufficient to explain much of the drop in initial claims in recent years. Nonetheless, they provide a plausible explanation for some of the decline.

The unexpected relative fall in the IUR brings into question its continued usefulness as a trigger for extended or supplemental UI programs. In principle, the ideal unemployment rate trigger would measure how difficult it is for typical workers to find jobs should they become unemployed. The duration of unemployment insurance protection could then be tied directly to the difficulty of finding a job. This permits the unemployment insurance system to provide job losers with a relatively constant degree of income protection, irrespective of the current state of the labor market. The simplest measure of the difficulty of job finding is what might be called the job loser rate-the ratio of current job losers to the number of currently employed. By excluding any measure of the situation of job leavers, new entrants, and reentrants, the job loser rate focuses squarely on the job prospects faced by the population insured by unemployment insurance-job losers.

If the job loser rate is used as the standard, the IUR has become an increasingly poor measure of labor market conditions. Figure 3 shows the relation between the seasonally adjusted job loser rate and the seasonally adjusted IUR for 1967:1 through 1982:4. Before 1980 the quarter-to-quarter movements in these two indicators were quite similar, although the IUR tended to fall faster after the trough of a recession than did the job loser rate. ${ }^{18}$ Since 1980 there has been a marked departure of

18. The difference occurs because the IUR excludes from the numerator virtually all job losers who have been unemployed longer than twenty-six weeks and hence have exhausted regular jobless benefits. These long-term job losers are included in the numerator of the job loser rate. 
Figure 3. Insured Unemployment Rate and Job Loser Rate, 1967:1 to 1982:4 ${ }^{a}$ Percent

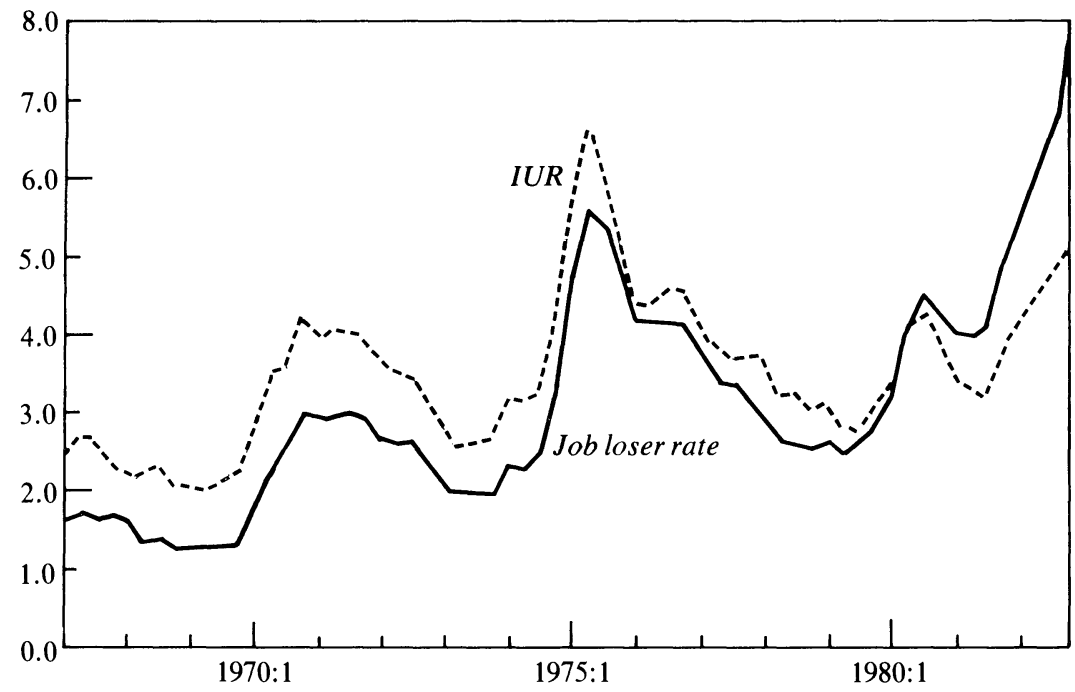

Source: U.S. Bureau of Labor Statistics. a. Seasonally adjusted quarterly data.

the IUR from its previous relation to job loss, for all the reasons mentioned above. The IUR, for example, seems to show that the job market situation was not markedly worse at the end of 1982 than it was at the low point of the 1970-71 contraction. The job loser rate, by contrast, was more than twice as high in 1982:3 as in 1970:4. Since the job loser rate seems to conform more closely with other measures of economic performance (payroll employment and GNP growth, for example), the IUR has apparently lost much of its value as an indicator of employment prospects for job losers.

Any substitute for the IUR in triggering extended jobless benefits should meet three criteria. It must specifically reflect the labor market situation of persons insured by unemployment insurance. It must be available in a timely manner, either weekly or monthly. And it must be available on a state-by-state basis. The job loser rate meets the first two of these criteria, but not the third because the CPS data sample is too small to permit accurate estimation of the number of job losers in each state. Hence any reform of the trigger mechanism for extended benefits must be based, at least in part, on administrative statistics compiled in 
the unemployment insurance system, which are accurate on the state level.

The trigger mechanism could be substantially improved by using the job loser rate as a national trigger that determines the number of added weeks of extended benefits to be available, on average, throughout the country. Individual states would then be allocated specific increments in benefit duration in proportion to their local insured rates, with states having a low IUR receiving very small increments and those with a high IUR, much larger increments. While this proposal does not entirely circumvent defects of the IUR as a measure of local labor market conditions, it at least makes it impossible for the extended benefit program to be reduced as the labor situation worsens-the situation that occurred in 1981-82.

Whatever its fate in triggering extended unemployment benefits, the insured unemployment rate should be temporarily retired as a serious measure of labor market conditions. 


\section{Comments and Discussion}

Lawrence H. Summers: This valuable paper begins with a striking empirical fact. During 1982 about 45 percent of the unemployed received unemployment insurance benefits, compared with 78 percent in 1975 . Burtless is careful to separate this decline into two components. In part, the decline in the fraction of the unemployed receiving unemployment insurance (UI) reflects conscious choices by policymakers. Congress chose not to reenact the federal supplemental benefits program that prolonged UI coverage to sixty-five weeks during 1975 and 1976. It also enacted legislation cutting back on the extended benefit program by raising state "trigger" levels. But this is not the whole story. The insured unemployment rate, which counts only persons covered under regular state UI programs, has declined sharply relative to the overall unemployment rate in the past several years. As Burtless notes, the total unemployment rate in 1982 exceeded the insured unemployment rate by 5.0 percent compared to a gap of only 2.6 percent in 1975 .

I want first to comment on the decline in the insured unemployment rate. Burtless begins by showing that a regression of insured unemployment on the number of recent job losers has significant negative residuals in recent years. He concludes from this that there is a puzzle to be explained and looks for clues. As a check on his procedure I used the May 1976 job search survey in which individuals report both reason for unemployment and whether they are collecting UI. I found that about 30 percent of job losers were not collecting UI, and that more than 20 percent of UI beneficiaries were classified as job leavers or reentrants. Perhaps it would be useful to explore more carefully the relation between the breakdown of unemployment by reason and the insured unemploy- 
ment rate. Similarly, I suspect Burtless's regressions of new UI claimants on recent job losses could also be improved.

Burtless finds that a large part of the aberrant behavior of insured unemployment during the recent recession is a consequence of fewer persons claiming benefits than would have been predicted from past historical relations. He attributes at least part of this decline to the taxation of UI benefits and to the reformed treatment of pensions and social security income in determining UI benefits. I find the tax explanation implausible. Many UI recipients were not subject to tax particularly in 1980 and 1981 before the Tax Equity and Fiscal Responsibility Act lowered the income floors. Recall that the taxes on unemployment insurance are typically at low rates and there is no withholding. Only Jack Kemp could think that a 33 percent tax payable in a year could deter someone from applying for UI.

My guess is that it is the perception of tightened eligibility rules and more rigorous enforcement that accounts for the decline in the number of UI claimants. Certainly the new administration tried to convey this impression. I have been told but cannot cite evidence that when "welfare crackdowns" are announced in individual states the welfare rolls contract even if no real changes are implemented. Burtless challenges this interpretation by noting that disqualification rates have not increased. This is not inconsistent with my story. By deterring potential cheaters from trying to get benefits, a crackdown might actually reduce the disqualification rate. To take a parallel example, a very successful police force might find that it had to make very few arrests.

The second part of Burtless's paper is written from the heart; no effort is made to conduct the sort of careful examination of evidence that characterizes the first part. He makes no secret of where he stands regarding current policy, writing "Some of the specific reforms . . . were quite sensible. But the collective effect of the reforms was to significantly reduce income protection and countercyclical stimulus from unemployment compensation in the midst of the worst economic downturn since the Great Depression."' Obviously value judgments are crucial here. But Burtless does not look very hard at the facts. Few believe that recent fiscal policy has been too restrictive. Indeed the ratio of disposable income to GNP was 0.71 in 1982 , its highest level since 1950 . What about income protection? It is important to note that the majority of federal 
supplementary benefits went to secondary workers. Close to half of the beneficiaries were married women and a substantial fraction were under age twenty-five. Only one-seventh of beneficiaries of these federal supplements provided sole support for a family.

A thorough exploration of the merits of current unemployment insurance policies would require an analysis of the trade-off between adverse incentives created by the UI system and the benefits of the insurance it provides. The latter consideration depends on the characteristics of UI beneficiaries and the extent to which their unemployment is forecastable. The former depends on a number of aspects of the behavior of both employees and their employers. A comparison of current levels of unemployment insurance with past levels is hardly a sufficient basis for analysis. Without a more careful analysis than the paper provides, policy conclusions are not warranted.

\section{General Discussion}

Robert Solow suggested that the insured unemployment statistics may be increasingly understating true unemployment because of the rise in women's participation in the labor force. In Switzerland, which bases its labor force statistics on unemployment insurance rather than on sample surveys, economists suspect that a portion of joblessness goes unrecorded because women fail to collect the unemployment benefits to which they are entitled. Martin Neil Baily added that the same malefemale differential in registering for benefits was observed in the United Kingdom, where unemployment insurance statistics are also used to measure joblessness. Burtless reported that a smaller fraction of unemployed women than unemployed men receive jobless benefits in the United States, though this did not necessarily mean that a smaller fraction of eligible unemployed women collected benefits. It is likely that a smaller fraction of the women unemployed are eligible for benefits because a greater fraction are new entrants and reentrants to the labor market. While the increase in the number of women participating in the labor force has been important in the decline of the IUR/TUR ratio, the rise in the number of young labor force participants in the 1960s and early 1970 s was also important.

Following the suggestion of Lawrence Summers that the relative 
reduction in unemployment insurance paid in the recent recession may have moderated wage demands, there was a spirited discussion of whether wage growth had moderated more than one might have expected. James Duesenberry was impressed by how closely most existing Phillips curve equations have been predicting recent wage inflation. George Perry agreed with Duesenberry that a short-run Phillips curve model could explain wage inflation fairly well through most of 1981 and 1982 , but thought that wage growth in recent months had slowed more than those models would predict. He observed that one should expect a prolonged and deep recession to induce shifts in wage norms by now, which would account for the low rate of wage inflation thus far in 1983. William Fellner thought the evidence for an unexpected drop in wage inflation went back further than 1983, but agreed that it might take several consecutive quarters of overpredictions before one could be confident that wage inflation was really unexpectedly low.

Baily pointed out an apparent inconsistency between the view that wage inflation was more moderate than expected in 1982 because of low jobless benefits and the often-heard view that a growing fraction of those reporting themselves as unemployed are not actively seeking work. The former view suggests that wage demands were restrained because an unusually large number of the unemployed were in serious need of earned income since they were not receiving benefits. The latter view asserts that an unusually large number of the reported unemployed were not seriously looking for work and could not be expected to keep down wage demands.

Burtless responded to the criticism of Summers, that the ratio of value judgment to fact was high in the second section of the paper. He noted that value judgments were nowhere stated in the text, although readers or critics might form their own. With respect to the point made by Summers, that disposable income held up well in the 1981-82 recession despite the relative decline in unemployment compensation, Burtless noted that the composition of disposable income had evidently changed in comparison to earlier recessions, with the long-term unemployed receiving relatively less. Apart from whatever value judgments one might draw from this, the previous pattern of unemployment compensation would have provided a still stronger automatic stabilizer to the economy without permanently enlarging the structural budget deficit. 